\title{
Parafibromin Staining Characteristics in Urothelial Carcinomas and Relationship with Prognostic Parameters
}

\author{
Serap Karaarslan · Banu Yaman ${ }^{1}$ \\ Hakan Ozturk ${ }^{2}$ \\ Banu Sarsik Kumbaraci ${ }^{1}$ \\ Department of Pathology, Sifa University \\ Faculty of Medicine, Izmir; \\ 1Department of Pathology, Ege University \\ Faculty of Medicine, Izmir; \\ 2Department of Urology, Sifa University \\ Faculty of Medicine, Izmir, Turkey \\ Received: February 26, 2015 \\ Revised: August 5, 2015 \\ Accepted: August 10, 2015 \\ Corresponding Author \\ Serap Karaarslan, MD \\ Department of Pathology, \\ Sifa University Faculty of Medicine, \\ Sanayi Caddesi №. 7, Bornova, Izmir 35100, Turkey \\ Tel: +90-232-343-4445 \\ Fax: +90-232-343-5656 \\ E-mail: serapkaraarslan@gmail.com
}

\begin{abstract}
Background: Parafibromin is a recently defined tumor suppressor gene. The aim of our study was to determine the relationships of parafibromin expression in urothelial carcinomas (UCs) with prognostic parameters and to evaluate the use of parafibromin as a potential marker of UC. Methods: Parafibromin expression was assessed in 49 UC specimens using immunohistochemistry. The correlations between parafibromin expression and clinical and pathologic parameters were investigated. Results: Of the patients, 42 (85.7\%) were male, and the mean age was 69.6 \pm 8.2 years (range, 54 to 88 years). Morphologically, the UCs were divided into two groups: papillary $(n=27)$ and non-papillary $(n=22)$. There were seven low-grade $(14.3 \%)$ and 42 high-grade $(85.7 \%)$ tumors. Parafibromin was negative in 13 tumors (26.5\%), partially positive in 19 tumors (38.8\%), and positive in 17 tumors (34.7\%). Parafibromin expression was more negative in UCs from upper urinary locations $(n=17)$ and with muscularis propria invasion $(n=28)$, which was statistically significant $(p=.009$ and $p=.007$, respectively). There was no statistically significant relationship between parafibromin expression and gender, age, tumor grade, survival, or disease-free survival. Conclusions: We found that UC cases with parafibromin positivity had less of a tendency to show muscularis propria invasion and were more commonly located in the lower urinary system. These results need to be confirmed with studies based on larger case series.
\end{abstract}

Key Words: Parafibromin; Urothelial carcinoma; Muscularis propria; Papillary; Non-papillary
Urothelial neoplasms are the most common urinary tract cancers and can be located in the lower (bladder and urethra) or upper (pelvocalyceal cavities and ureter) urinary tract. Bladder tumors make up 90\%-95\% of all urothelial malignancies, ${ }^{1}$ while upper urinary tract urothelial carcinomas (UUTUCs) are uncommon and make up only $5 \% .^{2-4}$ The natural history of bladder tumors and UUTUCs differ; $60 \%$ of UUTUCs, but only $15 \%$ of bladder tumors, are found to be invasive at the time of diagnosis. ${ }^{5-7}$ Tumor stage, histological grade, lymph node involvement, and type of surgical procedure used have been shown to be significant prognostic factors for urothelial carcinomas. ${ }^{8-10}$ Several classical clinicopathological, morphometric, cytometric, immunohistochemical, and molecular markers have also been shown to have prognostic significance, but the search for markers that affect patient outcome continues.

Parafibromin is a protein encoded by the hyperparathyroidism 2 (HRPT2) tumor suppressor gene. Mutations of this protein lead to autosomal dominant hyperparathyroidism-jaw tumor syndrome with parathyroid adenoma or carcinoma, mandibular or maxillary fibro-osseous tumors, and renal neoplastic and nonneoplastic abnormalities such as Wilms' tumor, hamartoma, or cystic renal disease. ${ }^{11-13}$ The HRPT2 gene, located in human chromosome 1q31.2, consists of 17 exons and spans $18.5 \mathrm{~kb}$ in the genome. The 2.7-kb transcript that it encodes is translated into a 531-amino acid parafibromin protein with a molecular weight of $60 \mathrm{kD} \cdot{ }^{14,15}$ This gene might function as a tumor suppressor gene as HRPT2-inactivating mutations have been reported in various malignancies. ${ }^{16-21}$ These findings suggest a potential role of parafibromin in the pathogenesis and progression of malignancy.

The role of the newly discovered tumor suppressor gene parafibromin in urothelial carcinoma has not been investigated. We evaluated the immunohistochemistry of parafibromin expression in urothelial carcinoma and paired benign urothelium from patients undergoing transurethral resection, radical cystectomy (RC), and nephroureterectomy. The aim was to investigate the expression of parafibromin in urothelial carcinoma and to determine its role in tumor behavior and prognosis in urothelial carcinoma (UC) patients. 


\section{MATERIALS AND METHODS}

\section{Patient and tissue selection}

The study cohort consisted of 49 cases diagnosed as urothelial carcinoma at a single center between January 2006 and December 2013. A total of 49 surgical specimens from 21 transurethral resections, 11 radical cystectomies, and 17 nephroureterectomies were retrospectively reviewed. Survival periods were calculated based on patient demographics. All patients provided consent for use of their tumor tissue for clinical research, and the Sifa University Ethics Committee approved the research protocol. We assessed patient medical charts for clinical features such as progression, recurrence, and presence and number of near and distant metastases.

\section{Histopathological evaluation}

All surgical specimens were processed according to standard pathology procedures and were histologically confirmed to be urothelial carcinoma. Tumor grading was performed according to the 2004 World Health Organization-International Society of Urological Pathology Consensus Classification. ${ }^{22}$ Tumor architecture was defined as papillary or non-papillary based on

Table 1. Clinical and histopathological features of the patients

\begin{tabular}{lc}
\hline Clinical and histopathological features & No. of cases (\%) \\
\hline Gender & \\
Male & $42(85.7)$ \\
Female & $7(14.3)$ \\
Tumor type & \\
Papillary UC & $27(55.1)$ \\
Non-papillary UC & $22(44.9)$ \\
Tumor grade & \\
Low & $7(14.3)$ \\
High & $42(85.7)$ \\
Muscularis propria invasion & \\
Present & $21(42.8)$ \\
Absent & $28(57.2)$ \\
Latest health status & \\
Alive & $46(93.9)$ \\
Dead & $3(6.1)$ \\
Recurrences & \\
Present & $20(40.8)$ \\
One & $14(28.6)$ \\
More & $6(12.2)$ \\
Absent & $29(59.2)$ \\
Progression ${ }^{a}$ & \\
Absent & $30(61.2)$ \\
Present & $19(38.8)$ \\
\hline
\end{tabular}

UC, urothelial carcinoma.

aProgression is accepted when the tumor developed invasive features/ deep invasion/lymph node metastasis/distant organ metastasis. the predominant feature of the index lesion.

\section{Immunohistochemical evaluation of parafibromin}

Formalin-fixed and paraffin-embedded tissue specimens were prepared for immunohistochemical (IHC) staining for all patients. A demonstrative block containing benign urothelium tissue adjacent to the tumor was selected for IHC evaluation. Sections 4-5- $\mu \mathrm{m}$-thick were prepared from the paraffin-embedded tissues and were placed on electrostatic-charged slides (Xtra, Surgipath Medical Industries, Richmond, IL, USA). Sections were deparaffinized and dehydrated through a graded ethanol series using routine protocols. The IHC study was performed using parafibromin (1:100, HRPT2, Santa Cruz Biotechnology, Santa Cruz, CA, USA). Slides from parathyroid adenoma cases were used as positive controls. The IHC staining process, including deparaffinization and antigen retrieval, was performed on a Dako LV-1 automated immunostaining system (Dako, Glostrup, Denmark). Scoring was performed separately by two pathologists who were blinded to patient characteristics. Nuclear staining was accepted as positive for parafibromin. The staining pattern was classified as diffusely and strongly positive when there was nuclear staining in all or nearly all (i.e., >95\%) of the tumor cells regardless of staining intensity, negative when there

Table 2. The relationship between tumor subtype and clinicopathologic parameters

\begin{tabular}{|c|c|c|c|}
\hline $\begin{array}{l}\text { Clinico-pathologic } \\
\text { parameters }\end{array}$ & $\begin{array}{c}\text { Papillary } \\
\text { subtype }(n=27)\end{array}$ & $\begin{array}{c}\text { Non-papillary } \\
\text { subtype (n=22) }\end{array}$ & $p$-value \\
\hline Gender & & & .385 \\
\hline Male & 3 & 4 & \\
\hline Female & 24 & 18 & \\
\hline Tumor grade & & & .01 \\
\hline Low & 7 & 0 & \\
\hline High & 20 & 22 & \\
\hline Muscularis propria invasion & & & .001 \\
\hline Absent & 19 & 2 & \\
\hline Present & 8 & 20 & \\
\hline Tumor localization & & & .153 \\
\hline Upper urinary system & 7 & 10 & \\
\hline Lower urinary system & 20 & 12 & \\
\hline Latest health status & & & .071 \\
\hline Alive & 27 & 19 & \\
\hline Dead & 0 & 3 & \\
\hline Recurrences & & & .110 \\
\hline \multicolumn{4}{|l|}{ Present } \\
\hline One & 5 & 9 & \\
\hline More & 5 & 1 & \\
\hline Absent & 17 & 12 & \\
\hline Progression & & & .683 \\
\hline Absent & 17 & 13 & \\
\hline Present & 10 & 9 & \\
\hline
\end{tabular}


was almost no staining $(<1 \%)$ of tumor nuclei, and partially positive in all other cases. ${ }^{17} \mathrm{~A}$ negative result was reported only if there was an internal positive control. There was no difference between the grades of the two pathologists.

\section{Statistical data analysis}

The SPSS ver. 18.0 (SPSS Inc., Chicago, IL, USA) software program was used for statistical analyses. In addition to descriptive statistical methods, the chi square test and Fisher exact test were used for the comparison of categorical variables. Binary numerical data were compared with the Mann-Whitney U test. Survival data were obtained with Kaplan-Meier, log rank, and Cox regression analyses. A p-value of $<.05$ was accepted as statistically significant.

\section{RESULTS}

\section{Clinical and pathological parameters}

The mean age was $69.55 \pm 8.2$ years (range, 54 to 88 years), and men made up $85.7 \%(n=42)$ of the group. Table 1 presents the clinicopathological features of the subjects. The follow-up range was 3 to 96 months. There were three deaths due to tumor during follow-up. Tumor progression (including development of invasive features, deep invasion, lymph node metastasis, and distant organ metastasis) was seen in 19 cases. Mean survival duration was $37.88 \pm 29.6$ months. Mean disease-free progression in the recurrence-free cases was $26.98 \pm 26.2$ months. There was a statistically significant relationship between tumor subtype and tumor grade and muscularis propria invasion $(\mathrm{p}=.01$ and $\mathrm{p}=.001$, respectively) (Table 2). All low-grade non-invasive tumors were of the papillary subtype, while high-grade tumors were mainly of the non-papillary subtype. Invasion was found in five of six high-grade UCs with squamous differentiation. There was no statistically significant relationship between tumor subtype and tumor localization, gender, age, presence or number of recurrences, presence of progression, survival, or disease-free survival (Table 2).

Table 3. The relationship between parafibromin expression and clinicopathologic parameters

\begin{tabular}{|c|c|c|c|c|}
\hline \multirow{2}{*}{ Clinicopathologic parameter } & \multicolumn{3}{|c|}{ Parafibromin expression } & \multirow{2}{*}{$\mathrm{p}$-value } \\
\hline & Negative & Partially positive & Positive & \\
\hline Gender & & & & .569 \\
\hline Male & 10 & 17 & 15 & \\
\hline Female & 3 & 2 & 2 & \\
\hline Tumor type & & & & .111 \\
\hline Papillary UC & 6 & 14 & 7 & \\
\hline Non-papillary UC & 7 & 5 & 10 & \\
\hline Tumor grade & & & & .105 \\
\hline Low & 0 & 5 & 2 & \\
\hline High & 13 & 14 & 15 & \\
\hline Muscularis propria invasion & & & & .007 \\
\hline Absent & 1 & 12 & 8 & \\
\hline Present & 12 & 7 & 9 & \\
\hline Tumor localization & & & & .009 \\
\hline Upper urinary system & 9 & 4 & 4 & \\
\hline Lower urinary system & 4 & 15 & 13 & \\
\hline Latest health status & & & & .353 \\
\hline Alive & 13 & 19 & 14 & \\
\hline Dead & 0 & 0 & 3 & \\
\hline Disease-free survival & 13 & 19 & 17 & .311 \\
\hline Recurrences & & & & .573 \\
\hline \multicolumn{5}{|l|}{ Present } \\
\hline One & 2 & 6 & 6 & \\
\hline More & 1 & 2 & 3 & \\
\hline Absent & 10 & 11 & 8 & \\
\hline Progression ${ }^{\mathrm{a}}$ & & & & .183 \\
\hline Absent & 10 & 12 & 8 & \\
\hline Present & 3 & 7 & 9 & \\
\hline
\end{tabular}

UC, urothelial carcinoma.

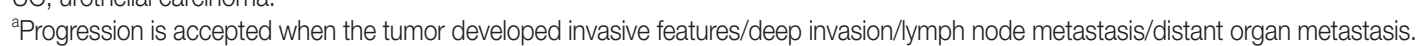




\section{The relationship between parafibromin expression and urothelial carcinoma}

Parafibromin expression was negative in 13 cases (26.5\%), partially positive in 19 cases (38.8\%), and positive in 17 cases $(34.7 \%$ ) (Table 3, Figs. 1-3). There was a statistically significant relationship between parafibromin expression and muscularis propria invasion and tumor location (upper/lower urinary system). It was interesting that parafibromin was more negative in UCs with muscularis propria invasion than in tumors that did not invade muscle $(\mathrm{p}=.007)$. Parafibromin expression was higher in tumors of the lower urinary system than in upper urinary system tumors $(\mathrm{p}=.009)$. There was no statistically significant relationship between parafibromin expression and gender, age, tumor grade, presence and number of recurrences, presence of progression, survival, or disease-free survival (Table 3). Parafibromin positivity in the normal urothelial epithelium adjacent to the tumor was seen in nine cases (Fig. 4). The positivity rate in normal urothelial epithelium was $50 \%$ to $90 \%$.

\section{DISCUSSION}

Parafibromin is a tumor suppressor gene that has attracted interest for its potential prognostic value in some tumor types, especially parathyroid tumors. Its use as a potential indicator of tumor aggressiveness has been reported in other organs (e.g., colon, stomach, and breast). ${ }^{18,20,21}$ To the best of our knowledge, there has not been a study on parafibromin staining in UCs in the English literature. The main aim of this study was to contribute to establishing criteria that can predict the behavior of tumors in suspect cases. We also evaluated the presence of statistically significant relationships between parafibromin staining and other prognostic parameters. Parafibromin expression was
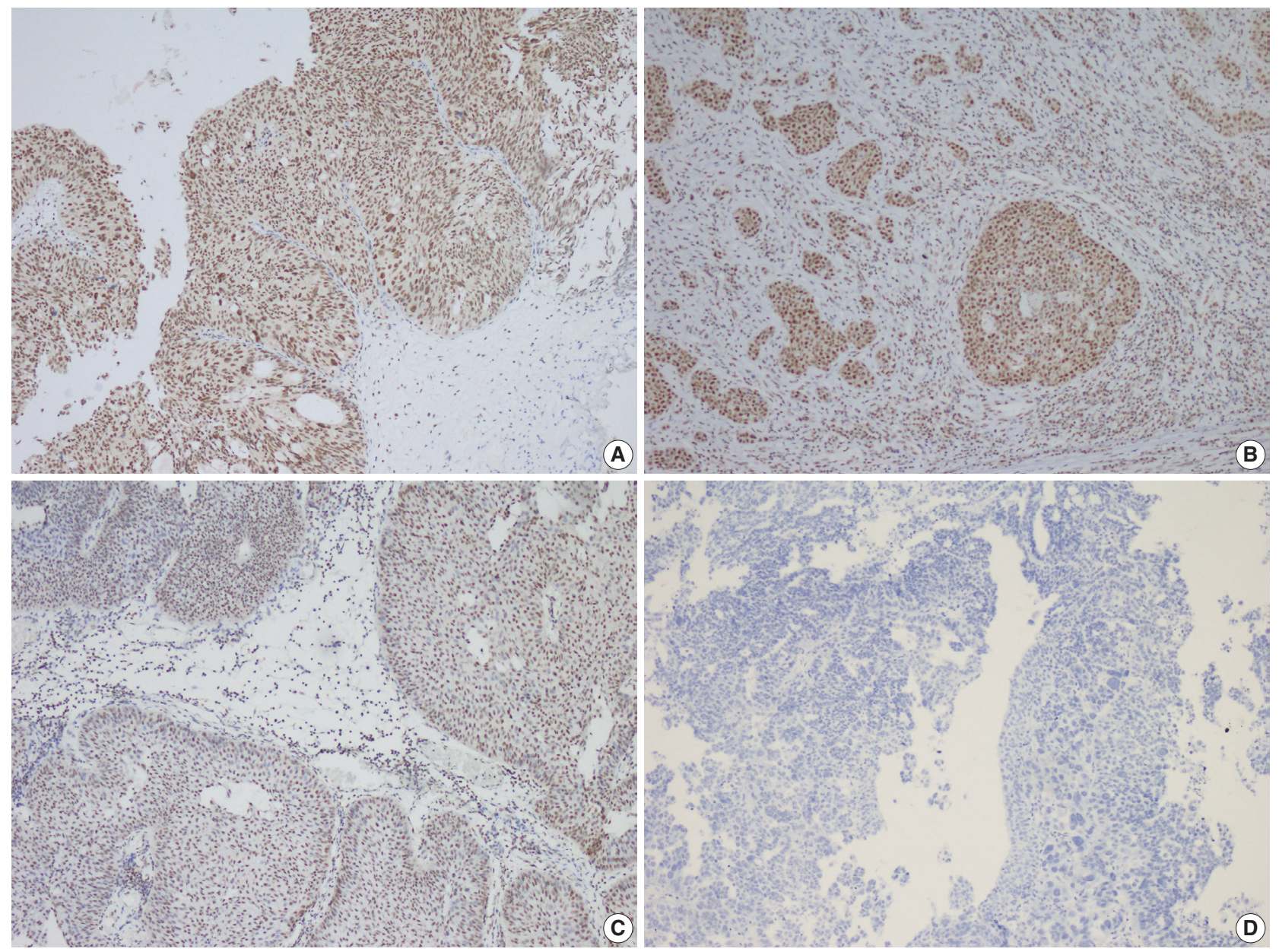

Fig. 1. Parafibromin staining in differant types of urothelial carcinomas. (A) Parafibromin positivity on immunohistochemical evaluation of noninvasive high-grade papillary urothelial carcinoma. (B) Parafibromin positivity in the invasive areas of high-grade urothelial carcinoma of the bladder. (C) Partial parafibromin positivity in non-invasive low-grade papillary urothelial carcinoma. (D) Parafibromin negativity in non-invasive high-grade papillary urothelial carcinoma. 
weaker in UCs with muscularis propria invasion than in those without invasion of the muscle. Parafibromin staining was more common in lower urinary system UCs than in those of the upper urinary system. The parafibromin staining data in our study correlates with that of previous parafibromin staining studies of malignancies of other systems. Selvarajan et al. ${ }^{18}$ observed an inverse correlation between tumor size and parafibromin expression in 163 breast carcinoma cases $(\mathrm{p}=.05)$. Zheng et al. ${ }^{20} \mathrm{ob}-$ served that lymph node metastasis and prognosis are related to parafibromin expression in colorectal carcinoma. Compared with the non-neoplastic colorectal mucosa, adenomas and carcinomas had decreased nuclear expression of parafibromin messenger RNA level. Zheng et al. ${ }^{21}$ also reported that parafibromin expression gradually decreased in carcinoma areas compared to the normal gastric mucosa areas, and statistically significant relationships between parafibromin and lymphatic invasion, invasion depth, lymph node metastasis, and tumor stage were observed. The rate of muscularis propria invasion in bladder carcinomas is estimated to be $20 \%-30 \%$ at the time of diagnosis. Muscularis propria invasion results in progression in 20\%-50\% of cases, even if the tumor is diagnosed early. ${ }^{23,24}$ We found a statistically significant relationship between parafibromin expression and muscularis propria invasion, which suggests that this biomarker can function as an indicator of progression.

The rate of upper urinary system recurrence (UUSR) following $\mathrm{RC}$ is low $(0.7 \%$ and $7.4 \%)$ but indicates a worse prognosis. The most important independent factors predicting UUSR following RC are number of metastatic lymph nodes and presence of local recurrence in the renal pelvis. ${ }^{25}$ We did not find a statistically significant relationship between parafibromin ex-
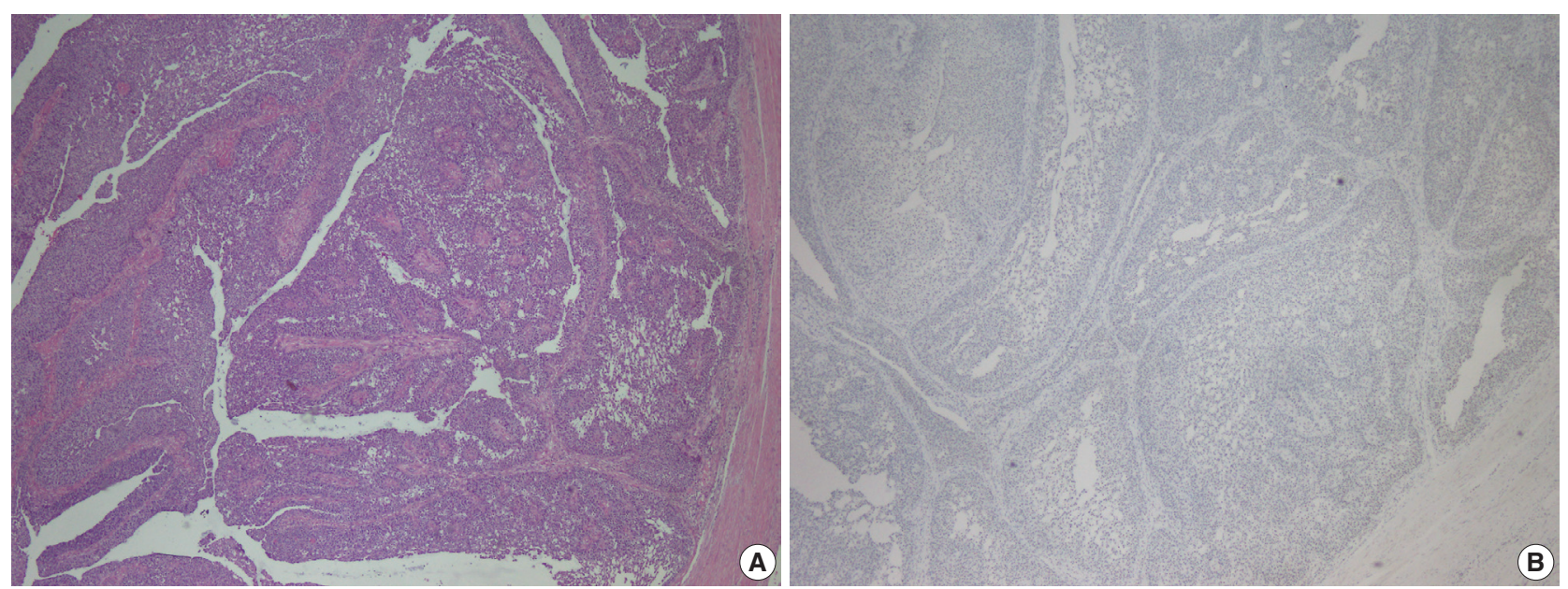

Fig. 2. Parafibromin negativity in minimally invasive high-grade papillary urothelial carcinoma of the ureter. (A) Morphological features of urothelial carcinoma. (B) Parafibromin negativity in the same tumor.
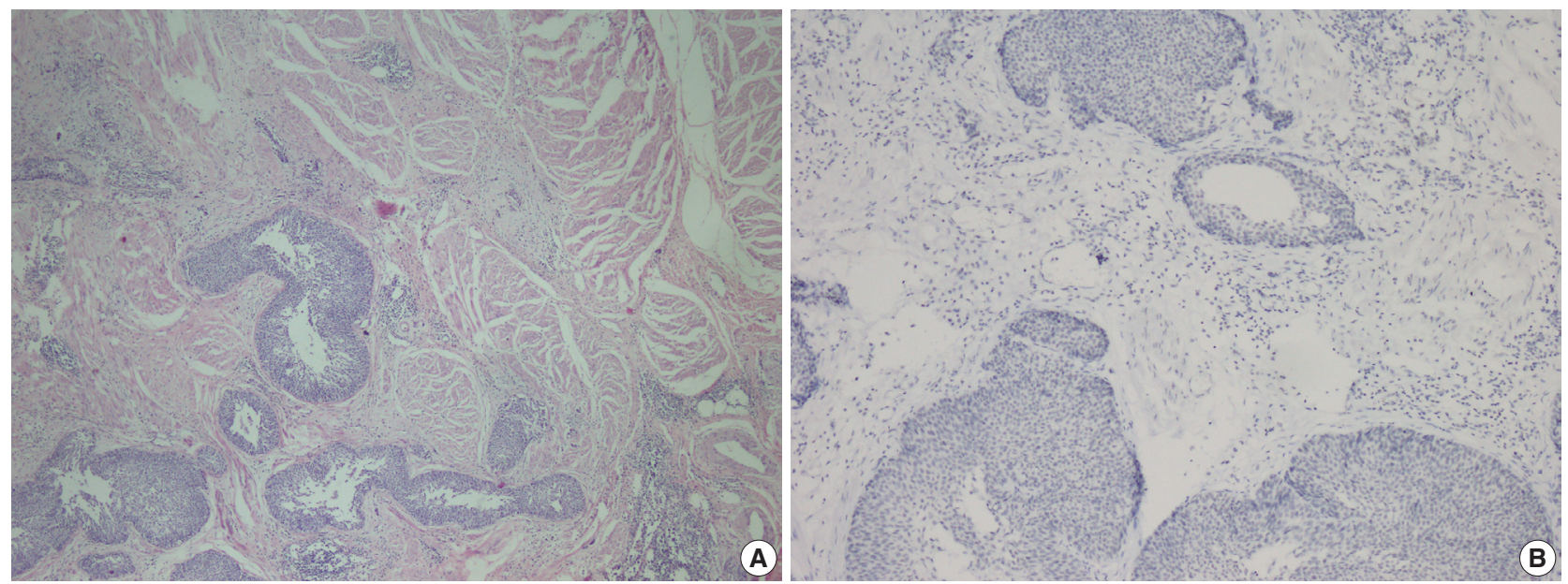

Fig. 3. Parafibromin negativity in invasive high-grade papillary urothelial carcinoma of the bladder. (A) Morphological features of urothelial carcinoma. (B) Parafibromin negativity in areas of muscularis propria invasion of the same tumor. 


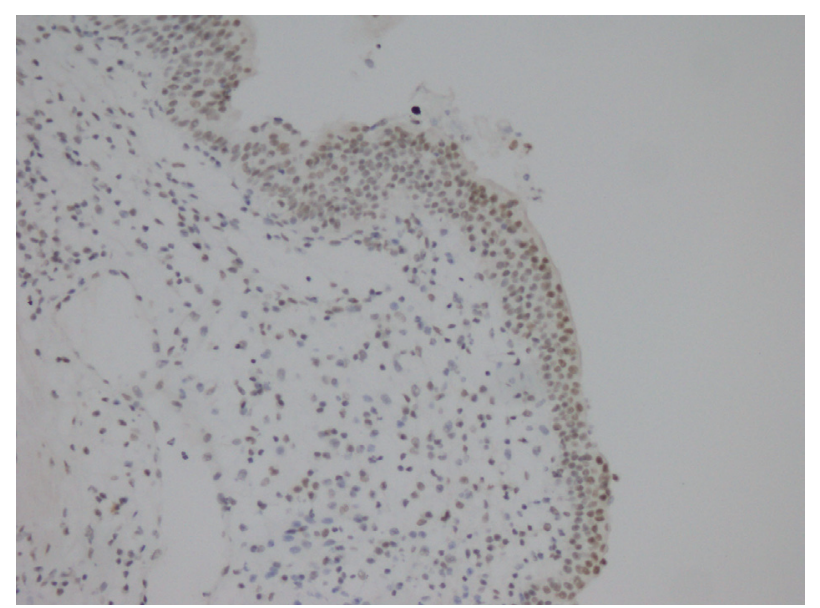

Fig. 4. Parafibromin positivity in normal urothelial epithelium.

pression and recurrence or progression in tumors that were removed by cystectomy, but parafibromin negativity was relatively prominent in recurring and progressive cases.

Urothelial carcinomas with squamous differentiation are known to have a poor prognosis. Their clinical course depends on the extension of the tumor to adjacent tissue and lymph nodes, requiring prompt radical surgery. Studies on the development mechanism and postoperative treatment of these tumors are ongoing. ${ }^{26}$ We did not find a marked difference in the diffuseness or intensity of parafibromin staining in the six tumors of this group (three were strongly positive, one was positive, and two were negative). However, two patients died (one with a tumor in the ureter, and the other with a tumor in the renal pelvis), which is consistent with data from the literature.

Although our study focused on UC, we also took into account the transition areas with normal urothelial epithelium during sample selection. All nine cases of normal urothelial epithelium in the observed areas were positive for parafibromin. Porzionato et al. ${ }^{27}$ have evaluated parafibromin staining in human and mouse tissues and reported that human bladder epithelium did not stain with parafibromin. However, the normal epithelium showed positive parafibromin staining in our cases. We are not sure of the cause of this discrepancy, but it could be related to differences in the parafibromin stain.

We found that the infiltration rate of the muscularis propria decreased in parafibromin-positive urinary system carcinomas. The parafibromin positivity rate was higher in carcinomas of the papillary type and in those of the lower urinary system. The question remains whether these features can be used as guiding parameters in tumor subgroups where the follow-up criteria have not been fully standardized, such as with papillary UCs. Pa- rafibromin expression was lower in higher-grade tumors, although this difference from lower-grade tumors was not statistically significant. Parafibromin negativity might provide guidance on adjuvant therapy in cases with poor prognostic parameters such as urothelial carcinoma with squamous differentiation. All of these statements require support from studies based on larger groups with longer follow-up periods.

\section{Conflicts of Interest}

No potential conflict of interest relevant to this article was reported.

\section{REFERENCES}

1. Ploeg M, Aben KK, Kiemeney LA. The present and future burden of urinary bladder cancer in the world. World J Urol 2009; 27: 289-93.

2. Jemal A, Siegel R, Ward E, Hao Y, Xu J, Thun MJ. Cancer statistics, 2009. CA Cancer J Clin 2009; 59: 225-49.

3. Margulis V, Shariat SF, Matin SF, et al. Outcomes of radical nephroureterectomy: a series from the Upper Tract Urothelial Carcinoma Collaboration. Cancer 2009; 115: 1224-33.

4. Oldbring J, Glifberg I, Mikulowski P, Hellsten S. Carcinoma of the renal pelvis and ureter following bladder carcinoma: frequency, risk factors and clinicopathological findings. J Urol 1989; 141: 1311-3.

5. Babjuk M, Oosterlinck W, Sylvester R, et al. EAU guidelines on non-muscle-invasive urothelial carcinoma of the bladder. Eur Urol 2008; 54: 303-14.

6. Hall MC, Womack S, Sagalowsky AI, Carmody T, Erickstad MD, Roehrborn CG. Prognostic factors, recurrence, and survival in transitional cell carcinoma of the upper urinary tract: a 30-year experience in 252 patients. Urology 1998; 52: 594-601.

7. Olgac S, Mazumdar M, Dalbagni G, Reuter VE. Urothelial carcinoma of the renal pelvis: a clinicopathologic study of 130 cases. Am J Surg Pathol 2004; 28: 1545-52.

8. Faraj SF, Chaux A, Gonzalez-Roibon N, et al. ARID1A immunohistochemistry improves outcome prediction in invasive urothelial carcinoma of urinary bladder. Hum Pathol 2014; 45: 2233-9.

9. Ramos Soler D, Ferrer Lozano J, Navarro Fos S, Llombart-Bosch A. Multiple analysis of morphologic factors with prognostic value in transitional cell papillary carcinoma of the bladder. Retrospective study of 571 cases. Actas Urol Esp 1999; 23: 119-26.

10. Schapers RF, Pauwels RP, Wijnen JT, et al. A simplified grading method of transitional cell carcinoma of the urinary bladder: reproducibility, clinical significance and comparison with other prognostic parameters. Br J Urol 1994; 73: 625-31.

11. Aldred MJ, Talacko AA, Savarirayan R, et al. Dental findings in a 
family with hyperparathyroidism-jaw tumor syndrome and a novel HRPT2 gene mutation. Oral Surg Oral Med Oral Pathol Oral Radiol Endod 2006; 101: 212-8.

12. Pimenta FJ, Gontijo Silveira LF, Tavares GC, et al. HRPT2 gene alterations in ossifying fibroma of the jaws. Oral Oncol 2006; 42: 735-9.

13. Shattuck TM, Välimäki S, Obara T, et al. Somatic and germ-line mutations of the HRPT2 gene in sporadic parathyroid carcinoma. N Engl J Med 2003; 349: 1722-9.

14. Carpten JD, Robbins CM, Villablanca A, et al. HRPT2, encoding parafibromin, is mutated in hyperparathyroidism-jaw tumor syndrome. Nat Genet 2002; 32: 676-80.

15. Wang PF, Tan MH, Zhang C, Morreau H, Teh BT. HRPT2, a tumor suppressor gene for hyperparathyroidism-jaw tumor syndrome. Horm Metab Res 2005; 37: 380-3.

16. Cetani F, Ambrogini E, Viacava P, et al. Should parafibromin staining replace HRTP2 gene analysis as an additional tool for histologic diagnosis of parathyroid carcinoma? Eur J Endocrinol 2007; 156: 547-54.

17. Gill AJ, Clarkson A, Gimm O, et al. Loss of nuclear expression of parafibromin distinguishes parathyroid carcinomas and hyperparathyroidism-jaw tumor (HPT-JT) syndrome-related adenomas from sporadic parathyroid adenomas and hyperplasias. Am J Surg Pathol 2006; 30: 1140-9.

18. Selvarajan S, Sii LH, Lee A, et al. Parafibromin expression in breast cancer: a novel marker for prognostication? J Clin Pathol 2008; 61: 64-7.

19. Tan MH, Morrison C, Wang P, et al. Loss of parafibromin immunoreactivity is a distinguishing feature of parathyroid carcinoma. Clin Cancer Res 2004; 10: 6629-37.

20. Zheng HC, Wei ZL, Xu XY, et al. Parafibromin expression is an in- dependent prognostic factor for colorectal carcinomas. Hum Pathol 2011; 42: 1089-102.

21. Zheng HC, Takahashi H, Li XH, et al. Downregulated parafibromin expression is a promising marker for pathogenesis, invasion, metastasis and prognosis of gastric carcinomas. Virchows Arch 2008; 452: 147-55.

22. Eble JN, Sauter G, Epstein JI, Sesterhenn IA. World Health Organization classification of tumours: pathology and genetics of tumours of the urinary system and male genital organs. Lyon: IARC Press, 2004; 90.

23. Quek ML, Stein JP, Clark PE, et al. Natural history of surgically treated bladder carcinoma with extravesical tumor extension. Cancer 2003; 98: 955-61.

24. Tilki D, Reich O, Svatek RS, et al. Characteristics and outcomes of patients with clinical carcinoma in situ only treated with radical cystectomy: an international study of 243 patients. J Urol 2010; 183: 1757-63.

25. Kim SH, Yang HK, Lee JH, Lee ES. A retrospective analysis of incidence and its associated risk factors of upper urinary tract recurrence following radical cystectomy for bladder cancer with transitional cell carcinoma: the significance of local pelvic recurrence and positive lymph node. PLoS One 2014; 9: e96467.

26. Rausch S, Hofmann R, von Knobloch R. Nonbilharzial squamous cell carcinoma and transitional cell carcinoma with squamous differentiation of the lower and upper urinary tract. Urol Ann 2012; 4: 14-8.

27. Porzionato A, Macchi V, Barzon L, et al. Immunohistochemical assessment of parafibromin in mouse and human tissues. J Anat 2006; 209: 817-27. 